\title{
Reply to Letter to the Editor
}

\section{The Sensitivity and Specificity of Ultrasound for the Diagnosis of Carpal Tunnel Syndrome}

\section{A Meta-analysis}

\author{
John R. Fowler MD, John P. Gaughan MD, \\ Asif M. Ilyas MD
}

Published online: 7 January 2011

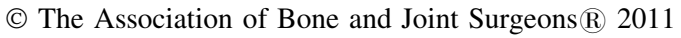

We thank Descatha et al. for their interest in our article [3] and their comments. A systematic review and metaanalysis uses a systematic approach to identify evidence from multiple studies to attain an accurate and unbiased estimate of the association between interventions or exposures and events that could be widely applicable to a larger population [4]. By combining patient data from multiple studies appropriately, meta-analyses allow for larger sample sizes and therefore statistical power to determine treatment effects [1, 4]. However, systematic reviews are not without limitations. All reviews are retrospective and observational and therefore are subject to random error and systematic bias [1]. Systematic reviews, when conducted properly, can provide a high level of evidence, improve the precision of the analysis by increasing the sample size, and help to explain differences in study results attributable to heterogeneity [2]. Ultimately, a meta-analysis depends on the quality of the primary studies included in the analysis [2]. We believe that we performed a quality meta-analysis [3], confirmed

Re: Fowler JR, Gaughan JP, Ilyas AM. The sensitivity and specificity of ultrasound for the diagnosis of carpal tunnel syndrome: a metaanalysis. Clin Orthop Relat Res. 2010 Oct 21. [Epub ahead of print]

J. R. Fowler $(\bowtie)$

Department of Orthopaedics, Temple University Hospital, 3401 N. Broad St, Philadelphia, PA 19140, USA

e-mail: fowler@temple.edu

\section{J. P. Gaughan}

Biostatistics Consulting Center, Temple University School of Medicine, Philadelphia, PA, USA

\section{A. M. Ilyas}

Rothman Institute, Thomas Jefferson University Hospital, 925 Chestnut Street, Philadelphia, PA, USA by high scores on the Oxman and Guyatt index [5], a validated scoring system for the quality of meta-analyses and systematic reviews.

Drs. Descatha, Huard, and Duval suggest that by combining studies that used different cross-sectional area cutoffs for positive diagnosis of carpal tunnel syndrome, our results may artificially influence the sensitivity and specificity of the sample. All meta-analyses carry this risk, and our study is no different. We agree that obtaining the raw data from all studies included in the analysis would have yielded more accurate results. However, as obtaining the raw data from every study is not possible, including only studies for which we were able to obtain raw data would introduce substantial selection bias. They also suggested that separate analyses should have been performed at each cross-sectional area cutoff value, however, this would decrease the sample size for each value and add more confusion to an already potentially confusing analysis. We thank Drs. Descatha, Huard, and Duval for observing our failure to include the likelihood ratios in the manuscript and have included a table detailing the ratios (Table 1).

We respectfully disagree that the specific transducer and ultrasound equipment used in each study is an important factor in the sensitivity and specificity of ultrasound as a diagnostic tool. We found no literature to support the advantage or disadvantage of one transducer over another. We did identify substantial heterogeneity in the criteria used for electrodiagnostic testing and clinical findings in the diagnosis of carpal tunnel syndrome. This heterogeneity, however, mirrors clinical reality where different institutions and physicians use varying criteria.

We sincerely thank Descatha et al. for their thoughtful comments and hope we have addressed their concerns. 
Table 1. Studies included in the meta-analysis [3] and reported likelihood positive and negative ratios

\begin{tabular}{|c|c|c|c|c|c|}
\hline Study* & $\begin{array}{l}\text { Reference } \\
\text { standard }\end{array}$ & $\begin{array}{l}\text { Cross-sectional } \\
\text { area cutoff }\left(\mathrm{mm}^{2}\right)\end{array}$ & $\begin{array}{l}\text { Number } \\
\text { of wrists }\end{array}$ & $\begin{array}{l}\text { Liklihood } \\
\text { ratio positive }\end{array}$ & $\begin{array}{l}\text { Likelihood } \\
\text { ratio negative }\end{array}$ \\
\hline Pinilla et al. [24] & Clinical & 6.5 & 70 & 13.5 & 0.11 \\
\hline Pastare et al. [23] & Clinical & 9 & 84 & & 0.38 \\
\hline Altinok et al. [1] & Clinical & 9 & 80 & 8.7 & 0.38 \\
\hline Padua et al. [22] & Clinical & 10 & 54 & & \\
\hline Visser et al. [27] & Clinical & 10 & 305 & 8.7 & 0.24 \\
\hline El Miedany et al. [5] & Clinical & 10 & 254 & & 0.02 \\
\hline Kwon et al. [14] & Clinical & 10.7 & 82 & 1.8 & 0.54 \\
\hline Kele et al. [12] & Clinical & 11 & 110 & 37.0 & 0.27 \\
\hline Wong et al. [30] & EDX & 9 & 96 & 2.7 & 0.09 \\
\hline Ziswiler et al. [32] & EDX & 9 & 101 & 2.8 & 0.20 \\
\hline Wong et al. [30] & EDX & 9 & 124 & 1.6 & 0.39 \\
\hline Duncan et al. [4] & EDX & 9 & 170 & 27.0 & 0.19 \\
\hline Ashraf et al. [2] & EDX & 9 & 150 & 3.6 & 0.26 \\
\hline Yesildag et al. [31] & EDX & 10.5 & 224 & 17.8 & 0.12 \\
\hline Sarria et al. [25] & EDX & 11 & 105 & 1.7 & 0.44 \\
\hline Weisler et al. [28] & EDX & 11 & 130 & 5.9 & 0.11 \\
\hline Moran et al. [17] & EDX & 12.3 & 70 & 12.4 & 0.40 \\
\hline Nakamichi and Tachibana [20] & EDX & 13 & 822 & 19.0 & 0.44 \\
\hline Lee et al. [15] & EDX & 15 & 100 & 22.0 & 0.13 \\
\hline
\end{tabular}

EDX = electrodiagnostic testing. (* Adapted from Table 1 in Fowler JR, Gaughan JP, Ilyas AM. The sensitivity and specificity of ultrasound for the diagnosis of carpal tunnel syndrome: a meta-analysis. Clin Orthop Relat Res. 2010 Oct 21 [Epub ahead of print].)

\section{References}

1. Bhandari M, Morrow F, Kulkarni AV, Tornetta P 3rd. Metaanalyses in orthopaedic surgery: a systematic review of their methodologies. J Bone Joint Surg Am. 2001;83:15-24.

2. Dijkman BG, Abouali JA, Kooistra BW, Conter HJ, Poolman RW, Kulkarni AV, Tornetta P 3rd, Bhandari M. Twenty years of metaanalyses in orthopaedic surgery: has quality kept up with quantity? J Bone Joint Surg Am. 2010;92:48-57.
3. Fowler JR, Gaughan JP, Ilyas AM. The sensitivity and specificity of ultrasound for the diagnosis of carpal tunnel syndrome: a metaanalysis. Clin Orthop Relat Res. 2010 Oct 21 [Epub ahead of print].

4. Montori VM, Swiontkowski MF, Cook DJ. Methodologic issues in systematic reviews and meta-analyses. Clin Orthop Relat Res. 2003;413:43-54.

5. Oxman AD, Guyatt GH. Validation of an index of the quality of review articles. J Clin Epidemiol. 1991;44:1271-1278. 